\title{
ZIKA VÍRUS E MICROCEFALIA EM RECIFE: IDENTIFICAÇÃO DE REDES REGIONAIS DE ASSISTÊNCIÀ À SAÚDE E EQUIPAMENTOS MÉDICO- ASSISTENCIAIS NOS ESTABELECIMENTOS ASSISTENCIAIS DE SAÚDE PARA O ENFRENTAMENTO DO ZIKA VÍRUS E MICROCEFALIA NO PERÍODO DE 2015-2016
}

\section{$\underline{\text { A. P. S. BARBOSA }}{ }^{1}$, J. E. LORENA SOBRINHO ${ }^{2}$; F. H. C. OLIVEIRA ${ }^{3}$}

\author{
${ }^{1}$ Universidade de Pernambuco, Faculdade Ciências Médicas, IC/PIBIC \\ ${ }^{2}$ Universidade de Pernambuco, Faculdade Ciências Médicas, Graduação em Saúde Coletiva \\ e Pós-Graduação em Hebiatria \\ ${ }^{3}$ Universidade de Pernambuco, Faculdade Ciências Médicas, Graduação em Saúde Coletiva \\ e Medicina
}

E-mail para contato: ana.160198@gmail.com

\begin{abstract}
RESUMO: Identificar a existência das Redes Regionais de Assistência à Saúde e equipamentos médico-assistenciais nos Estabelecimentos Assistenciais de Saúde para o enfrentamento do Zika vírus e microcefalia no periodo de 2015-2016. Trata-se de uma pesquisa analítica, com abordagem quanti-qualitativa, tendo como cenário ou contexto a epidemia do Zika Vírus no município de Recife durante os anos de 2015 e 2016. A busca de informações dos dados epidemiológicos será através do acesso ao Sistema de Informações sobre Orçamentos Públicos em Saúde e pelo Cadastro Nacional de Estabelecimentos de Saúde. A partir da identificação e análise das informações, constatou a não existência de uma rede especifica de apoio para as crianças com microcefalia, já que, a assistência está inserida dentro das redes assistenciais existente, em que, determinados profissionais especializados já estão inclusos. No momento, Recife possui 120 Unidades Básicas de Saúde como porta de entrada na atenção básica para o acesso a assistência as gestantes com suspeitas de fetos com microcefalia e aos recém-nascidos, constatando um único serviço municipal especifico para o atendimento destas crianças, onde se localiza na Policlínica Lessa de Andrade. O trabalho faz parte de um projeto de pesquisa de iniciação científica, tendo como objetivo final a identificação dos estabelecimentos assistenciais e dos custos envolvidos com a Síndrome do Zika Virus no Recife.
\end{abstract}

Palavras-chave: Saúde Pública, Atenção Básica, economia e microcusteio.

ABSTRACT: Identify the existence of Regional Health Care Networks and medical and health care facilities in Health Care Facilities to address Zika virus and microcephaly in the period 2015-2016. This is an analytical research, with a quantitative-qualitative approach, having as scenario or context the Zika Virus epidemic in the municipality of Recife during the years 2015 and 2016. The search 
for information on epidemiological data will be through access to the Information on Public Budgets in Health and the National Registry of Health Establishments. Based on the identification and analysis of the information, it verified the lack of a specific network of support for the children with microcephaly, since, the assistance is inserted within the networks in which certain specialized professionals are already included. At present, Recife has 120 Basic Health Units as a gateway to basic care for access to care for pregnant women with suspected fetuses with microcephaly and newborns, noting a single specific municipal service for the care of these children, where located at Lessa de Andrade Polyclinic. The work is part of a research project of scientific initiation, with the ultimate goal of identifying the care centers and costs involved with the Zika Virus Syndrome in Recife.

Keywords: Public Health, Basic Attention, economics and microcountries.

\section{INTRODUÇÃO}

As Redes de Atenção à Saúde (RAS) carecem de ser eficientes e efetivas considerando a integralidade na atenção à saúde, de acordo com as ações e serviços para a melhoria da qualidade e integralidade dos serviços para a população (BRASIL,2016). No que se refere ao Zika vírus, o MCTI - Ministério da Ciência Tecnologia e Inovação definiu a saúde como tema estratégico para o triênio 2016 a 2019, observando uma política de prevenção, controle, diagnóstico e tratamento de determinadas doenças, especialmente as arboviroses (BRASIL, 2015). Sendo importante ressaltar a desigualdade de oferta e utilização nos acessos a insumos e bens de serviços de saúde, os equipamentos médico-assistenciais são essenciais para o enfrentamento destas doenças, como microcefalia provocada pelo Zika vírus, mesmo percebendo as inúmeras dificuldades para o enfrentamento e suas futuras consequências na população (FRANÇA et al., 2016).

Diante desses fatos ao entorno dos fatores etiológicos do Zika Vírus e suas consequências na população, a gestão dos Sistemas Municipais de Saúde vivencia inúmeras dificuldades para o enfrentamento do problema, as quais precisam ser objeto de pesquisa acadêmicas. Pesquisas sobre este tema permitirá apropriação devida sobre os recursos empregados e necessários para tomadas de decisão pelos gestores dos sistemas de saúde, seja em quaisquer esferas de governo, para a solução desse e de novos problemas de saúde pública, apontando estratégias que conseguiram produzir impactos e métodos para a sua condução.

Assim, o objetivo do trabalho é a identificação da existência das Redes Regionais de Assistência à Saúde (RRAS) e equipamentos médico-assistenciais (EMA) nos Estabelecimentos Assistenciais de Saúde (EAS) para o enfrentamento do Zika vírus e microcefalia no período de 2015-2016.

A importância deste tipo de trabalho para as áreas de gestão, economia e saúde, mostra-se de grande relevância, tanto pelo estudo da epidemia de Zika vírus e microcefalia, como pela identificação importante no serviço que são as Redes Regionais de Assistência à Saúde (RRAS) e equipamentos médico-assistenciais (EMA) nos Estabelecimentos Assistenciais de Saúde (EAS) direcionadas para o enfrentamento dessa doença, uma vez que, é urgente e estratégico para a gestão do SUS o levantamento desses dados para futuras ações direcionadas. 


\section{MATERIAIS E MÉTODOS}

\subsection{Tipos de estudo}

Trata-se de pesquisa analítica, seguindo os procedimentos metodológicos da análise de conteúdo sugeridos por Bardin (2011), onde se destacam a categorização, a inferência, a descrição e a interpretação, com abordagem quanti-qualitativa, tendo como cenário ou contexto a epidemia do Zika Vírus no município de Recife durante os anos de 2015 e 2016 seus impactos e estratégias de enfrentamento pelo sistema municipal de saúde.

\subsection{Local de estudo e período de estudo}

O estudo está sendo desenvolvido no município de Recife, capital de Pernambuco. Como locais para coleta dos dados: estabelecimentos de atenção primária, especializada em saúde, Complexo Hospitalar da UPE, bem como a sede da Secretaria Municipal e Estadual de Saúde do Recife e de Pernambuco, respectivamente. A execução deste projeto de pesquisa se dará em doze meses compreendendo o período de 01/08/2017 a 31/07/2018, conforme EDITAL PIBIC-IC/UPE/CNPq - 2017/2018. Os dados apresentados neste trabalho correspondem a primeira parte deste projeto, a partir de fontes secundárias de agosto à outubro corrente.

\subsection{Coleta e análise de dados}

A coleta de dados transcorreu a partir da observação nas bases de cadastro do Sistema de Informações sobre Orçamentos Públicos - SIOPS e Cadastro Nacional de Estabelecimentos de Saúde - CNES, coletando e examinando a quantidade de estabelecimentos assistenciais em saúde e centros específicos que atendem mães e crianças afetadas pela Síndrome do Zika vírus. Consequentemente, analisando a porcentagem dos custos gerais/ indiretos com a saúde, uma vez que, estando direcionada também ao atendimento das mesmas.

\section{RESULTADOS E DISCUSSÃO}

A partir da identificação e análise das informações, constatou a não existência de uma rede de apoio específica para as crianças com microcefalia, já que, a assistência está inserida dentro das redes assistenciais existente, em que, determinados profissionais especializados já estão inclusos na rede. O município do Recife, como preconizado pela PNAB - Política Nacional de Atenção Básica, encontra-se dentro de uma rede assistencial, ofertando o acesso para as mães e crianças afetadas com o Zika vírus. No momento, Recife possui 120 Unidades Básicas de Saúde como porta de entrada na atenção básica para o acesso a assistência as gestantes com suspeitas de fetos com microcefalia e aos recém-nascidos.

Recife tem um único serviço municipal específico para o atendimento de crianças com microcefalia, onde se localiza na Policlínica Lessa de Andrade contendo como profissionais: 01 pediatra, 01 fonoaudióloga, 01 terapeuta ocupacional, 01 psicólogo, 01nutricionista, 01 assistente social e 01 fisioterapeuta e 02 neuropediatras. Contudo, qualquer ponto da rede pode ser acessado por estas mães e crianças, não necessariamente para um atendimento específico, mas para algum atendimento clinico inerente aos serviços ofertados por aquelas unidades serviços. 
Diante desta identificação será necessário a continuação da pesquisa buscando custo direto para o enfrentamento da Síndrome do ZIKA Vírus, na rede de saúde instalada, visto que, no momento foi identificado apenas custo geral/indireto.

\section{CONCLUSÃO}

Portanto, o trabalho faz parte de um projeto de pesquisa de iniciação científica, tendo como objetivo final a identificação dos estabelecimentos assistenciais e dos custos envolvidos com a Síndrome do Zika Vírus no Recife. Nesta publicação foi alcançada a primeira parte do projeto, uma vez que, identificamos a estratégia do enfrentamento desta Síndrome no que tange a organização da assistência básica.

\section{REFERÊNCIAS}

BARDIN, L. Análise de conteúdo. Ed. I - Revista e Ampliada. Edições 70, Brasil, 2011.

BRASIL, Ministério da Saúde. Secretaria Executiva. Departamento de Economia da Saúde, Investimento e Desenvolvimento. Secretaria de Ciência, Tecnologia e Insumos Estratégicos. Departamento de Ciência e Tecnologia. Mapeamento e diagnóstico da gestão de equipamentos médico-assistenciais nas regiões de atenção à saúde do projeto QualiSUS-Rede / Ministério da Saúde, Secretaria de Ciência, Tecnologia e Insumos Estratégicos, Departamento de Ciência e Tecnologia. - Brasília: Ministério da Saúde, 2016.172 p.

BRASIL, Ministério da Saúde. Secretaria de Ciência, Tecnologia e Insumos Estratégicos. Departamento de Ciência e Tecnologia. Política Nacional de Gestão de Tecnologias em Saúde. Brasília: Ministério da Saúde, 2010. 48 p.BRASIL. Ministério da Saúde. Plano nacional de enfrentamento à microcefalia. Brasília, 2015.

FRANÇA, G. V. A. et al. Congenital Zika virus syndrome in Brazil: a case series of the first 1501 livebirths with complete investigation, Lancet (British Edition), v. 16, jun. 2016.

\section{AGRADECIMENTOS}

Agradeço, ao meu orientador pelo auxilio na construção e no avanço da pesquisa, ao CNPQ, uma vez que, me concedeu a bolsa para dar andamento ao trabalho, e por fim, a instituição ao qual faço parte como graduanda para desenvolvimento do meu conhecimento. 